High-Performance Work System and Employee Performance: The Mediating

Roles of Social Exchange and Thriving and the Moderating Effect of

Employee Proactive Personality

\author{
M N Akhtar \\ Junwei Zhang \\ P. Matthijs Bal \\ Lirong Long \\ Yong Zhang \\ Zixiang Ma
}

Manuscript Accepted for Publication in

Asia Pacific Journal of Human Resources 


\section{High-Performance Work System and Employee Performance: The Mediating Roles of Social Exchange and Thriving and the Moderating Effect of Employee Proactive Personality}

High-performance work system (HPWS) research is mainly drawn from theories of social exchange and human capital to unlock the underlying mechanisms in relation to employee performance. In addition to both theories, a personal resources perspective can also be used to explain the effects of HPWS. In this cross-level research, we tested the mediating mechanisms of social exchange, and thriving, alongside proactive personality as a moderating variable in the relationships between HPWS and task performance and organizational citizenship behavior (OCB) by analyzing the sample of 391 employees and 84 supervisors from 21 firms in China. Using multilevel analyses, social exchange and thriving were found to have mediated the effect of HPWS on employee task performance and OCB. Furthermore, proactive personality attenuated HPWS's direct effect on thriving and indirect effect on employee task performance and OCB through thriving.

Keywords: high-performance work system (HPWS); social exchange; thriving; task performance; proactive personality; organizational citizenship behavior 


\section{Introduction}

Research has suggested that high-performance work system serves as an important component that enables organizations to become more effective and get competitive advantage (Zhang et al., 2018; Aryee et al., 2012; Toya et al., 2009; Bowen \& Ostroff, 2004; Liao et al., 2009,). Highperformance work system (HPWS) refers to as the application of internally coherent, consistent and steady human resource practices intended in improving employee commitment, their competence as well as motivation (Aryee et al., 2012; Datta et al., 2005). Several researchers presented that HPWS is linked with number of desirable consequences for employees such as higher organizational citizenship behavior (OCB)improved performance (Zhang et al., 2018; Kehoe \& Wright, 2013; Jiang et al., 2013), increased organizational commitment and job satisfaction (Korff, Biemann, \& Voelpel, 2017; Messersmith, Patel, \& Lepak, 2011; Takeuchi, Chen, \& Lepak, 2009).

Given the positive impacts of HPWS on employee outcomes, researchers have shown keen interest in explaining how HPWS affects its presumed outcomes. Extant research is drawn from two prominent theories i.e. human capital, and social exchange to unlock the fundamental mechanisms in HPWS studies (Kehoe \& Collins, 2017; Jianget al., 2012). A social exchange process states that employees see HPWS as benefits received from the organization and thus, reciprocate by engaging in task performance and OCB. A human capital view implies that HPWS can enhance employees' abilities, skills, and knowledge needed to perform better. In addition to developing a strong employee-employer relationship and enhancing employees' human capital, HPWS may carry more meanings for employees because excellent performance not only requires reciprocation (i.e., social exchange perspective) and employees' knowledge and skills (i.e., human capital approach), but also requires employees' personal resources, especially when 
encountering sustained stress or challenge (Buruck et al, 2016). "Personal resources are positive self-evaluations that are linked to resiliency and refer to individuals' sense of their ability to control and impact upon their environment successfully" (Xanthopoulou et al., 2009 p. 236). It is essential to explore how to promote personal resources because they act as an important influencer towards employee behaviors (Clauss et al., 2018; Gilbert, Foulk, \& Bono, 2018). But, this view is not seen in HPWS research. Thriving is a key personal resource (see Gerbasi et al., 2015) as it refers to the psychologically combined act of learning as well as vitality at workplace (Spreitzer et al., 2005).

Conservation of resources theory (COR) further explains the significance of personal resources by assuming individuals having resources are likely to use them to gain new resources, a process referred to as the gain spiral effect (Hobfoll, 2001). Likewise, HPWS may have the potential to induce resources gain spirals. When individuals are thriving through obtaining resources from HPWS, they have sufficient resources to engage in OCB and task performance. Therefore, we extend the HPWS research by examining the mediating role of thriving between HPWS and employee task performance and OCB beyond social exchange and human capital mechanisms.

Finally, it is argued that thriving may differ among employees because they vary in their needs for HPWS. As the investment in HPWS is costly, it is critical to identify the conditions where organizations can reap more benefits from HPWS. Previous HPWS research has almost exclusively focused on the situational factors, for example team characteristics i.e. task complexity, and team cohesion (Chang et al., 2014), and leadership styles (Jiang, et al., 2015). However, less is known about how personality traits moderate the effects associated with HPWS. As HPWS is theorized to offer employees resources in their work to conduct their jobs more 
effectively, a crucial issue pertains to which employees benefit most from HWPS. Employees who are by personality not proactive may particularly be interested in HPWS. HPWS offers a system in which employees have an entitlement towards resources. This may be especially beneficial for workers low in proactivity, as they may be less inclined to negotiate special arrangements and may depend strongly on HPWS that offers a more structured, collective approach to motivate them (Bakker et al., 2012). That is, proactivity is likely to serve as a key moderator distinguishing between those workers who need HPWS to be able to thrive at work and those who are able to ensure thriving and performance without necessarily relying upon HPWS. Thus, it is argued that the influence of HPWS on thriving may be contingent upon employee proactive personality.

\section{Literature Review and Hypotheses Development}

Our study focuses on HPWS comprising a range of HR best practices (comprehensive and rigorous recruitment \& selection, training \& development, participative decision making, performance based pay packages, and information sharing) and innovative work design processes that if utilized in bundles or certain combinations, bring mutually reinforcing synergistic benefits (Zhang et al 2018; Ubeda-Garcia et al., 2018; Jiang, 2013; Sun et al., 2007). Thus, the reasoning behind HPWS focus is that the joint impact of different components of HR best practices have stronger influence than the sum of individual ones (Aryee et al., 2012). Moreover, HR best practices when bundled have been found to have stronger relationship towards firm performance than individual practices combined (Subramony, 2009). Therefore, we examine HPWS in line with prior literature and in a view that these HR best practices be considered as synergistic.

Our study conceptualizes HPWS at the department-level. Department supervisors play a 
pivotal role in carrying out HPWS (Brewster et al., 2013; Sikora \& Ferris, 2014). Accordingly, researchers usually used department supervisors to report HPWS (Jensen, Patel, \& Messersmith, 2013; Pak \& Kim, in press; Sikora, Ferris, \& Van Iddekinge, 2015). Variability frequently occurs at department-level because department supervisors may vary in competence and willingness to deal with HR affairs, workload, and HR responsibility (Kuvaas, Dysvik, \& Buch, 2014; Vermeeren, 2014). As a result, we operationalize HPWS at the department-level, as the department is the crucial level in between organizational policies and employee experiences of available policies and practices.

Several theoretical viewpoints have been utilized to unlock the black-box in HPWS research. Specifically, several authors have employed social exchange theory explaining the mediating mechanism of HPWS in relation to organizational commitment and perceived organizational support as the mediators (Kehoe \& Wright, 2013; Messersmith et al., 2011). Furthermore, some researchers have argued that human capital is the major contributor of productivity as well as a source to sustain the competitive advantage for the organization (Jiang et al., 2012). HPWS exerts an important role in attracting, fostering, and retaining talents, which is beneficial for organizational operational and financial performance (Jiang et al., 2013).

Personal resources, and in particular thriving, are different from social exchange and human capital views on HPWS as it is referred to the abilities, knowledge, and the skillset, of employees (Liao et al., 2009). "Personal resources are positive self-evaluations that are linked to resiliency and refer to individuals' sense of ability to control and impact upon their environment successfully" (Xanthopoulou et al., 2009 p. 236). Human capital and personal resources have some overlap but also considerable differences. Personal resources are similar to human capital in that they refer to the resources that are subtle or intangible, however, can be managed, 
developed and measured for effective job-oriented performance (Clauss et al., 2018; Liao et al., 2009). Nevertheless, personal resources and human capital have some important differences. First, personal resources focus on the positive psychological state that reflects how individuals evaluate themselves, whereas human capital is employees' abilities, knowledge, and skillset that are utilized at work. Second, personal resources are "who you are", whereas human capital is "what you know". 1

Following the underlying mechanism of reciprocity under social exchange theory which proposes that individuals who receive favors from another party are likely to return these benefits as they feel obligated to repay the favors (Blau, 1964). In contrast, thriving does not solely create felt obligations of individuals to reciprocate by increasing their efforts to the organizations because thriving results from a process of accumulating resources in line with the conservation of resource theory (Hobfoll, 1989).

\section{HPWS on Employee Task Performance and OCB}

First, we test the influence processes of HPWS on the outcome variables (employee task performance and OCB) and argue that HPWS is positively related with employee task performance, and OCB by facilitating social exchange and thriving. ${ }^{2}$ Task performance refers to

\footnotetext{
${ }^{1}$ We thank the anonymous reviewer for this suggestion.

${ }^{2}$ We thank the anonymous reviewer for this suggestion. To examine the incremental contribution of thriving in explaining how HPWS affects employee task performance and OCB, we should control for the explanations of social exchange theory (i.e., social exchange) and human capital theory. In our study, social exchange is treated as a key variable rather than a control variable in that prior research commonly adopted perceived organizational support and commitment as the proxy variables of social exchange perspective to explore the underlying mechanisms associated with HPWS (Kehoe \& Wright, 2013; Liao et al., 2009; Messersmith et al., 2011), and did not directly measure social exchange. Hence, it is imperative to theorize and test the mediating role of social exchange between HPWS and employee performance. Additionally, extant work employed human capital theory to investigate the influence process of HPWS by directly measuring employees' competence, knowledge, and human capital as the mediators (Chang \& Chen, 2011; Liao et al., 2009; Liu, et al., 2017; Lopez-Cabrales et al., 2009). Thus, the human capital mechanism (i.e., competence) is included as a control variable in our study.
} 
employees' behaviors that are assigned to accomplish their formal job requirements. In contrast to task performance, OCB is referred as "extra-role performance that is discretionary, not directly or explicitly recognized by the formal reward system, and in the aggregate promotes the efficient and effective functioning of the organization" (Organ, 1988: p. 4). Task performance and OCB can be distinguished based on work behaviors that come under the limits of formal job requirements and are relevant employee consequences to both personal resources, and social exchange.

\section{The Mediating Role of Social Exchange}

Social exchange theory (SET) offers rationale for explaining how HPWS affects employee performance and suggests that when individuals get favors from the other party, are likely to exchange benefits to the giver in return (Blau, 1964). SET is defined as "favors that create diffuse future obligations, not precisely specified ones, and the nature of the return cannot be bargained about but must be left to the discretion of the one who makes it" (Blau, 1964: 93). Similarly termed as, a long-term and socio-emotional exchange relationship and is characterized by commitment, obligation and mutual trust between employees and organizations (Colquitt et al., 2014). withdrawing upon the social exchange theory, employees enjoying higher-level of social exchange are likely to reciprocate the beneficial treatment by behaviors that the organization values (e.g., task performance and OCB). Prior work has also shown the positive links between social exchange and employee task performance and OCB (Song et al., 2009; Shore et al., 2006).

It is further argued that HPWS will increase social exchange relationship between employees and their organizations. HPWS encompassing HR practices such as extensive training, comprehensive recruitment, rigorous selection, and performance management 
mechanisms reflecting organizational investment in employees' development, and communicate messages with employees regarding organizations' intentions to develop long-term relationships with them (Takeuchi, Lepak, Wang, \& Takeuchi, 2007). HR best practices e.g. flexible job designs, participation based decision-making, and performance-based compensation show organizations' trust, and recognition for employees (Liao et al., 2009). Likewise, HPWS is interpreted by employees as expressing trust, recognition, as well as investment—all signaling a social exchange perspective (Shore et al, 2006). Thus, we postulate that social exchange acts as a potential connection where HPWS influences employee task performance and OCB.

Hypothesis 1a: Social exchange mediates between HPWS and employee task performance. Hypothesis 1b: Social exchange mediates between HPWS and OCB.

\section{The Mediating Role of Employee Thriving}

We introduce personal resources, and in particular employee thriving, as an explanatory mechanism between HPWS and employee performance. According to Spreitzer et al., (2005: 538) thriving is "the psychological state in which individuals experience both a sense of vitality and a sense of learning at work". Where, vitality is the affective component of thriving, refers to individuals have energy and zest for work and learning is referred to as acquiring and applying the skills, and new knowledge, which represents a cognitive part of thriving. Gerbasi et al. (2015) of the view that thriving can be perceived as a personal resource. Drawing upon this argument, we postulate that employees can experience more thriving through the resources offered by HPWS.

COR theory helps to explain how HPWS contributes to employee performance through the mediating role of thriving and argues that individuals try their best to keep, protect, develop, and invest resources at work. Accodring to Hobfoll (1989: 516) resources are "the objects, personal 
characteristics, conditions, or energies that are valued by the individuals". COR theory states that individuals having access to extra resources are prone to reinvest these resources to realize resources gain spiral (Hobfoll, 2001). Hence, in accordance with COR theory, HPWS contributes to the accumulation of resources for employees, including learning and vitality as the indicators of thriving at work. Furthermore, COR theory explains that when employees have access to resources, and thrive at work, they are enabled to perform better and engage in OCB. In sum, thriving is likely to follow from HPWS, and relates to higher task performance and OCB.

According to Spreitzer et al, (2005: 538) that agentic work behaviors i.e. "task focus, exploration, and heedful relating are the engine of thriving" that enhance thriving. Task focus is the level of individuals' concentration on their job requirements. Exploration occurs when individuals seek new ways to work through experimentation, risk taking, unearthing, and innovative behaviors. Heedful relating describes that individuals pay more attention to coworkers' needs. The effectiveness of three agentic work behaviors in boosting thriving has been supported in previous studies (Paterson et al., 2014; Niessen et al., 2012).

We assume that HPWS, which includes practices e.g. comprehensive and rigorous recruitment \& selection, training \& development, participative decision making, performance based pay packages, and information sharing, may enable three agentic work behaviors and therefore, employee thriving. Comprehensive recruitment and rigorous selection help firms acquire individuals with required skills and knowledge that are crucial for task performance. Extensive training provides individuals the necessary skills and knowledge to complete their tasks (Jiang et al., 2012). Information sharing encourages employees to disseminate their knowledge and information with their coworkers. When performance management has a developmental purpose (i.e., as a developmental performance management), it informs 
employees about improvements in their knowledge, skills, and performance (Chang et al., 2014).

The enhanced knowledge and skills resulting from these five HR practices enable employees to be absorbed in their work. In addition to fostering task focus, these HR practices also contribute to exploration. Learning theory suggests that employees learn by developing associations between the current knowledge of individuals and the new domains of learning, and it increases when the overlap occurs between what is already known and the new knowledge (Ellis, 1965). A large amount of knowledge resulting from these five HR practices is advantageous for individuals to construct links between the current knowledge and the new knowledge with ease (Chang et al., 2014), which facilitates exploration and learning. Such enhanced exploration further leads to employee thriving. Finally, when employees have wide variety of skills, and knowledge are likely to understand the interconnections of tasks between themselves and coworkers, and pay attention to coworkers' needs (Carmeli \& Spreitzer, 2009). Such heedful relating ultimately promotes employee thriving. Research also suggested that knowledge resources enhance these three agentic work behaviors and consequently, employee thriving (Niessen et al, 2012; Spreitzer et al., 2005).

Other aspects of HPWS e.g. flexible job designs, and participation-oriented decisionmaking contribute to employee thriving via agentic work behaviors. Flexible job designs and participation in decision-making are often associated with enhanced job autonomy (Chang et al., 2014; Aryee et al., 2012; Liao et al., 2009). Individuals who feel autonomous will be more able to experience work responsibilities, which lead them to concentrate on their work i.e., task focus (Spreitzer \& Porath, 2014; Spreitzer et al., 2005). In addition, when employees experience autonomy in work, are more likely to have an opportunity to perform heedful relating (Spreitzer et al, 2005). Thus, it is argued that flexible job design and participative decision-making offer job 
autonomy to employees which in turn augments agentic work behaviors. These agentic work behaviors further enhance employee thriving.

Furthermore, flexible job design also reflects organizational trust for employees, as organizations believe in them and allow them to volitionally arrange their tasks. Participation in decision-making demonstrates organizational acceptance for employees' recommendations, that shows appreciation and trust for them. Performance-based compensation conveys signals of organizational recognition for employee contributions (Gardner et al, 2011; Liao et al., 2009). Employees who feel organizational trust and recognition are more involved and motivated in their work and engage in heedful relating (Carmeli \& Spreitzer, 2009; Spreitzer et al., 2005). Moreover, organizational trust and recognition also induce exploratory behaviors, in part because employees feel safe to take risks (Spreitzer \& Porath, 2014). Taken together, HPWS enhances thriving by offering employees with knowledge and skills, and by creating a better environment in which employees experience the sense of autonomy, trust, and recognition, which are the critical sources of agentic work behaviors necessary for thriving.

In line with COR theory, we further argue that thriving will positively predict employee task performance and OCB. As mentioned above, employees can be thriving through the resources provided by HPWS. When employees are thriving, they have extra resources available to engage in task performance, and OCB. More specifically, vitality represents the affective component of thriving, which is pivotal to employee task performance and OCB (Fredrickson, 2001; Porath et al., 2012). Furthermore, OCB is a way to learn new things, and learning is inherent in thriving (Spreitzer \& Porath, 2014). Thus, employees who feel thriving are likely to perform OCB. Some empirical studies showed the positive impact of thriving on task performance and OCB (Porath et al., 2012; Spreitzer \& Porath, 2014). Therefore, we maintain that the link between HPWS and 
task performance and OCB occur in part through employee thriving.

Hypothesis 2a: Thriving mediates between HPWS and task performance.

Hypothesis $2 b$ : Thriving mediates between HPWS and OCB.

\section{Proactive Personality as a Moderator between HPWS and Employee Thriving}

The argument that HPWS enhances employee thriving is because employees have the same needs for resources provided by HPWS. The effectiveness of HPWS, however, will depend on the individual features of employees because they will vary in their needs for HPWS. In light of COR theory, we test the moderating role of employee proactive personality in HPWS-thriving link. Proactive personality termed as those individuals who take action to effect their environment (Bateman \& Crant, 1993). It differs from thriving in the following ways. In particular, it is the personality trait that determines the tendency to which people initiate changes in their environment (Bateman \& Crant, 1993), and differs from thriving as the latter refers to an experience of vitality and learning, which is not dispositional, but involvement climate, promotion focus (Wallace et al., 2016), supervisor support climate (Paterson et al., 2014), and political skill (Cullen et al., 2018).

Employee proactive personality is likely to moderate the relationship between HPWS and thriving because it is closely aligned with agentic work behaviors, which are crucial in this link. More proactive employees will be better able to acquire sufficient resources through their proactive behaviors and depend less on resources that are provided by HPWS to increase employee agentic work behaviors. ${ }^{3}$ Thus, HPWS will be specifically important for employees

\footnotetext{
${ }^{3}$ [We are thankful to the anonymous reviewer for this suggestion. Proactive personality belongs to neither personal resources nor human capital by its nature. Proactive personality is the personality trait that is difficult to be changed and malleable (Bateman \& Crant, 1993), whereas both personal resources and human capital can be built and enhanced with the help of training and interventions (Clauss et al., 2018; Gilbert et al., 2018; Liao et al., 2009). However, employees with high proactive personality acquire resources more easily than employees with low proactive personality (Bakker et al., 2012). This is a reason why we propose
} 
with low proactive personality to enhance thriving. By definition, proactive employees construct favorable conditions, and identify opportunities to improve things for themselves at work, regardless of whether the system has provided them with the necessary resources to do so (Crant, 2000). Their initiatives may result in behaviors such as updating their knowledge and skills (Seibert, Kraimer, \& Crant, 2001). Additionally, proactive employees are likely to ask for feedback and help from their coworkers and supervisors (Li, Harris, Boswell, \& Xie, 2011), which help to enrich their knowledge and skills.

Research also revealed that proactive personality is linked with increased motivation to learn (Brown et al., 2006; Major, Turner, \& Fletcher, 2006). Moreover, proactive employees effectively regulate their work behaviors and work environments, which contribute to a greater sense of autonomy (Greguras \& Diefendorff, 2010). As depicted above, these resources such as knowledge, skills, and senses of autonomy boost agentic work behaviors, and thus, ultimately lead to employee thriving. Instead, HPWS and proactive personality overlap in their functions to foster employee thriving. Therefore, the resources provided by HPWS are less important for employees having higher levels of proactive personality to increase thriving.

In contrast, HPWS is critical for less proactive employees to facilitate employee thriving. Rather than proactively shaping the environment, employees with low proactive personality only passively adapt to their work situations, fail to show initiative, and do not easily identify opportunity (Crant, 2000). Therefore, less proactive employees do not easily acquire resources such as autonomy. As Bakker et al. (2012) suggested that when comparing employees having higher proactive personality than lower are less likely to enrich their resources. In other words, employees with low proactive personality augment the need for resources provided by HPWS, making HPWS more important for thriving. Prior empirical study indirectly supports this idea. 
For instance, Li et al. (2011) demonstrated that developmental feedback has stronger impacts on task performance and helping for less proactive employees. So, we hypothesize:

Hypothesis 3: Proactive personality moderates between HPWS and employee thriving, such that the association is stronger when employee proactive personality is low than high.

Taken together, the combined relationships under study are summarized in a moderated mediation model. Though, the indirect effect depends upon employee proactive personality but specifically, thriving mediates between HPWS and employee task performance and OCB. For employees with low proactive personality, the link between HPWS and thriving will be stronger than for highly proactive employees. As a consequence, the indirect effect between HPWS and employee task performance (OCB) via thriving will be more prominent when proactive personality is low than high. Therefore, we hypothesize:

Hypothesis 4a: Proactive personality moderates the indirect effect of HPWS on employee task performance through thriving, such that the indirect effect is stronger when employee proactive personality is low than high.

Hypothesis 4b: Proactive personality moderates the indirect effect of HPWS on employee OCB through thriving, such that the indirect effect is stronger when employee proactive personality is low than high.

FIGURE 1 ABOUT HERE

Methods

\section{Participants and Procedure}

Data for the current study were collected from Shandong, Hubei, and Zhejiang Provinces in China. The sample consists of IT, electric power generation, and manufacturing sector firms. In order to overcome common method biasness, separate questionnaires were distributed to 
individuals and department supervisors with the attached cover letter explaining that i) the participation in this survey questionnaire is voluntary, ii) responses will be kept anonymous and confidential, and iii) the survey is solely for academic research purpose only. Thriving, proactive personality, social exchange, employee competence, and demographic information was responded by employees whereas the department supervisors rated the items of task performance and OCB for their subordinates. Furthermore, department supervisors also rated HPWS that the firms implemented for their department employees. Before administering the survey questionnaires, we contacted HR managers in each organization and explained them the requirement to select the departments randomly.

A total of 442 employees and 88 department supervisors from 21 firms participated in the data collection process. We utilized the questionnaire by matched code in order to identify each participant's response i.e. employees and the corresponding supervisor. In total we received 413 responses from employees (response rate $=93.44 \%$ ) and 86 supervisors (response rate $=$ 97.73\%). 22 employees and 2 supervisors had to be excluded, because 10 employees belonging to 2 departments whose supervisors failed to respond, 8 employee surveys with incomplete information, and 4 employees belonged to 2 departments in which less than 3 members had responded. So, bringing the final sample to 391 employees and 84 department supervisors from 21 firms with average respondents (employees) per department was 4.65 (ranging from 3 to 10 employees) male (53.20\%); undergraduate qualified were $82.10 \%$ whereas postgraduate were 5.63\%; average age $29.28(S D=5.80)$ years old; average tenure $4.69(S D=4.70)$ years. The average department size was $18.98(S D=14.58)$, average firm age 16.53 years $(S D=17.13)$ and number of employees were less than 500 (61.90\%).

\section{Measures}


We developed all the scale items in English language and then translated into Chinese language for final survey questionnaire distribution. Back-translation method was followed to guarantee the validity and reliability of these scales.

HPWS. For HPWS, we adopted the 18-items measure developed in the Chinese context by Jiang (2013). We conceptualized HPWS at the department-level, and it was targeted to measure HPWS that the firms implement for department employees. Department supervisors were asked to assess the use of HPWS, sample items are "The company invests considerable time and money in training for department employees", and "Performance appraisals provide department employees feedback for personal development." A 5-points Likert-type scale was utilized ranging from strongly disagree $=1$ to strongly agree $=5$. The means scores of all HR practices representing HPWS were calculated by following the previous literature recommendations (Aryee et al., 2012; Liao et al., 2009). The overall HPWS scale reliability (Cronbach's alpha) was $\alpha=0.91$. The loadings of the 18 -items utilized to measure HPWS were all higher than 0.62 , along with the Average Variance Extracted (AVE) value was 0.65, showing a relatively higher level of both the convergent validity and the internal consistency (Hair et al., 2013).

Task performance. We measured task performance by using 4-items based on a 7-points Likert-type scale (ranging from strongly disagree=1 to strongly agree=7) from Chen et al., (2002) and it was rated by department supervisors. A sample item is "Always completes job assignments on time." The overall scale reliability was $\alpha=0.90$, AVE was 0.70 , and the loadings for all 4-items were higher than 0.78 which shows higher level of convergent validity and internal consistency for the measure.

OCB. We used a 9-items based on 7-points Likert-type scale developed by Farh et al., (2007) to measure organizational citizenship behavior (OCB) and was rated by department 
supervisors The scale consists of three dimensions: altruism, voice, and conscientiousness. Altruism was measured by three items. A sample item is "Initiates assistance to coworkers who have a heavy workload." Voice was rated by two items. One sample item is "Actively raises suggestions to improve work procedures or processes." Conscientiousness includes four items. A sample item is "Willing to work overtime without receiving extra pay." The overall scale was $\alpha=$ 0.94, AVE was 0.63 and the loadings of the 9-items were higher than 0.73 displaying higher level of both convergent validity and internal consistency.

Thriving. For thriving, we utilized a 10-items measure from Porath et al. (2012). This scale consists of two dimensions: vitality and learning. Employees assessed five items representing vitality (e.g., "I feel alive and vital at work.") and five items representing learning (e.g., "I find myself learning often at work.") based on 5-point Likert scale items ranging from strongly disagree $=1$ to strongly agree $=5$. The overall scale was $\alpha=0.82$, AVE was 0.51 and the loadings of the 9-items were higher than 0.58 displaying higher level of both convergent validity and internal consistency.

Social exchange. We adopted an 8-item social exchange scale from Shore et al. (2006). Employees were instructed to report this scale on a 5-points Likert scale items ranging from strongly disagree $=1$ to strongly agree $=5$. A sample item is "My organization has made a significant investment in me." The overall scale was $\alpha=0.76$, AVE was 0.54 and the loadings of the 9-items were higher than 0.64 showing higher level of both convergent validity and internal consistency.

Proactive personality. We measured this variable using 10-items from Seibert et al., (1999) scale and it was rated by employees based on a 5-points Likert-type scale items ranging from strongly disagree $=1$ to strongly agree $=5$. A sample item is "I am constantly on the lookout for 
new ways to improve my life." The overall scale was $\alpha=0.86$, AVE was 0.497 and the loadings of the 9-items were higher than 0.64 showing higher level of both convergent validity and internal consistency.

Control variables. We controlled not only for employee demographics i.e. age, gender, tenure, and education but also for department size, firm size, and firm age. We included these control variables to test whether the outcome variables could be explained on the basis of the immediate contexts in which employees operate, and in particular the size of their departments and organizations. This also allows to rule out another explanation that HPWS may be more likely to be implemented in larger organizations, through which employee outcomes are facilitated by the fact that they are working in larger organizations rather than due to HPWS (Sun et al., 2007). We included firm age because it is linked with evolution or the implementation of HR best practices as well as learning curve gains in the performance (Guthrie, 2001). Finally, past studies have suggested that employee competence (e.g., human capital) mediates the effects

of HPWS (Nieves \& Quintana, 2018; Raineri, 2017; Aryee et al., 2016; Chang \& Chen, 2011; Liao et al., 2009;). Thus, it is controlled for employee competence and was measured by using a 3-items scale developed by Sheldon et al., (2001). A sample item is "I felt very capable in what I did." The overall scale was $\alpha=0.86$,

\section{Analytical Strategy}

The current data was based on nested structure because employees were nested under departments, and departments were nested under firms. Therefore, we utilized Hierarchical Linear Modeling (HLM-3) with HLM software in order to test hypotheses. First, the present study focused on department-level HPWS. To check whether this approach is appropriate, we ran a two-level null model with department-level HPWS (as the outcome variable). The result 
demonstrated that within-firm variance and between firm variance of department-level HPWS was 0.48 and 0.07 , respectively. Within-firm variance accounted for $87.3 \%$ of total variance, revealing a large proportion of variance in HPWS among different departments in the same organization. As a result, it is appropriate that we use department-level HPWS to test our research hypotheses.

We estimated the three-level null models with thriving, task performance, OCB, and social exchange as the outcome variables, respectively and demonstrated that within-department, between-department, and between firm variance of thriving were $0.27,0.13$, and 0.02 , respectively. ICC $(1)_{\text {department }}$ associated with thriving was $30.95 \%$. As such, ICC $(1)_{\text {department }}$ for task performance, OCB, and social exchange were $61.06 \%, 63.25 \%$, and $34.55 \%$, respectively. These results justified HLM as the appropriate analytical technique.

With regard to moderated mediation effects (Hypothesis $4 \mathrm{a}$ and $4 \mathrm{~b}$ ), we conducted a parametric bootstrap procedure recommended by Preacher \& Selig, (2012) to estimate the indirect effects at high and low (1 SD above/below mean, respectively) levels of the moderator and their effect differences. Moreover, we constructed the Monte Carlo confidence intervals adopting $\mathrm{R}$ software.

\section{Results}

\section{Confirmatory Factor Analyses}

We performed confirmatory factor analysis (several CFA models) to check the distintinctiveness of individual level factors in the study: thriving, social exchange, competence, task performance, OCB, and proactive personality. Following Little et al., (2002), we treated the first order dimensions of thriving (e.g., vitality and learning) and OCB (e.g., altruism, voice, and conscientiousness) as respective latent variables in the CFAs. Additionally, we developed 5- 
parcels of related items as indicators of proactive personality by taking averages of these items to the higher as well as lower loadings (Bagozzi and Edwards, 1998; please also see Lam et al., 2015). The results of CFA are presented in Table 1 where the six-factor model (baseline model) achieved the best fit among all models we examined, $\chi^{2}=768.99, d f=260, \chi^{2} / d f=2.96$, $\mathrm{RMSEA}=0.07, \mathrm{TLI}=0.90$, and CFI $=0.91$. The value of RMSEA meets the suggested criteria of below 0.08, and the values of TLI and CFI also meet the recommended criteria of at least 0.90 (Hoyle, 1995). Moreover, the Chi-square tests presented in Table 1 showed that the baseline model (six-factor) was more superior than all six alternate models. These results demonstrated the clear evidence for the distinctiveness of six variables in our study.

TABLE 1 ABOUT HERE

\section{Descriptive Statistics}

The results of mean, standard deviation (SD), and coefficient of correlation for all study variables are showed in Table 2 . Thriving was positively associated with task performance $(r=$ $0.33, p<0.001)$, and OCB $(r=0.27, p<0.001)$. Social exchange was positively associated to task performance $(r=0.22, p<0.001)$ and OCB $(r=0.16, p<0.01)$. The results demonstrated preliminary support for hypotheses.

TABLE 2 ABOUT HERE

\section{Hypotheses Testing}

The HLM analyses are showed in Table 3. As presented in Model 1, HPWS was positively associated to task performance $(\gamma=0.49, p<0.05)$. Likewise, Model 3 showed that HPWS was also positively related with $\mathrm{OCB}(\gamma=0.72, p<0.001)$.

TABLE 3 ABOUT HERE 
Hypothesis $1 \mathrm{a}, 1 \mathrm{~b}, 2 \mathrm{a}$, and $2 \mathrm{~b}$ proposed that social exchange and thriving will mediate the relationships of HPWS with employee outcomes. As reported in Table 3, HPWS was positively associated to social exchange $(\gamma=0.15, p<0.05)$ and thriving $(\gamma=0.19, p<0.05)$. Next, we simultaneously entered HPWS, thriving, and social exchange in Model 2 and 4. Results showed that social exchange was linked with higher task performance $(\gamma=0.20, p<0.05)$ and OCB $(\gamma=$ $0.16, p<0.05)$. Similarly, the relationships between thriving and two performance outcomes were significant (for task performance, $\gamma=0.16, p<0.05$; for OCB, $\gamma=0.11, p<0.05$ ). Whereas, the impacts of HPWS on outcomes i.e. task performance, $\gamma=0.38, p<0.05$; and OCB, $\gamma=0.58, p$ $<0.01$ ) became weaker than Model 1 and 3. Thus, Hypotheses 1a, 1b, 2a, and 2b were supported.

To justify the significance for the cross-level indirect effects, we followed a parametric bootstrap procedure written in R software as suggested by Preacher \& Selig (2012). With 20,000 Monte Carlo re-samples, the results revealed that there were positive indirect relationships between HPWS and task performance (indirect effect $=0.03,95 \% \mathrm{CI}=[0.002,0.070]$ ) and $\mathrm{OCB}$ (indirect effect $=0.021,95 \% \mathrm{CI}=[0.001,0.051])$ via thriving. Both confidence intervals excluded zero, demonstrating the significance of the indirect effects. Moreover, HPWS had significant indirect effects on task performance (indirect effect $=0.03,95 \% \mathrm{CI}=[0.001,0.074]$ ) and OCB (indirect effect $=0.024,95 \% \mathrm{CI}=[0.002,0.055]$ ) via social exchange. These results showed further backing for our Hypotheses $1(\mathrm{a} \& \mathrm{~b})$ and $2(\mathrm{a} \& \mathrm{~b})$.

Hypothesis 3 envisaged an interaction-term effect between HPWS, and proactive personality in relation to thriving. We followed group mean centering approach suggested by Hofmann \& Gavin (1998), for employee proactive personality and added group means of proactive personality, and the interaction term effect between HPWS and group mean of proactive personality when measuring cross-level interaction effect. Likewise, Model 6 showed 
that the interaction term of HPWS and proactive personality on thriving was significant $(\gamma=-$ $0.24, p<0.001)$. We plotted the moderating effect of proactive personality and calculated the simple slopes by following Aiken \& West (1991) procedure. We found a significant association (simple slope $=0.23, p<0.01$ ) between HPWS and thriving when proactive personality was low, but a nonsignificant relationship (simple slope $=-0.05, n s$ ) when proactive personality was high. Hence, Hypothesis 3 was fully supported.

\section{FIGURE TWO ABOUT HERE}

Hypothesis $4 \mathrm{a}$ and $4 \mathrm{~b}$ expected a moderated-mediation model where the indirect relationships between HPWS and outcomes via thriving vary with different levels of proactive personality. To examine these two hypotheses, we utilized the parametric bootstrap procedure again to examine the indirect effects of thriving at higher and lower level of proactive personality. The indirect effect for task performance was significant when proactive personality was low (indirect effect $=0.037,95 \% \mathrm{CI}=[0.008,0.078]$ ), but not significant when proactive personality was high (indirect effect $=-0.008,95 \% \mathrm{CI}=[-0.035,0.013])$. The indirect effect difference between the two levels was significant (difference $=-0.045,95 \% \mathrm{CI}=[-0.089,-$ 0.011]), lending support to Hypothesis 4a. Additionally, for OCB, the indirect effect was significant when proactive personality was low (indirect effect $=0.025,95 \% \mathrm{CI}=[0.002,0.056]$ ), but not significant when proactive personality was high (indirect effect $=-0.006,95 \% \mathrm{CI}=[-$ $0.025,0.009])$. The indirect effect difference between the two levels was significant (difference= $-0.031,95 \% \mathrm{CI}=[-0.066,-0.003])$. Therefore, Hypothesis $4 \mathrm{~b}$ was fully supported.

\section{Discussion}

The current study showed that as per the social exchange approach, social exchange mediated the impacts of HPWS on outcome variables i.e. employee task performance, and OCB. 
In addition, consistent with the personal resources explanation, thriving mediated the between HPWS and employee task performance and OCB, positively. Furthermore, the results showed that proactive personality moderated the indirect effects of HPWS on employee task performance and OCB through thriving, such that the indirect effects were stronger when proactive personality was low than high. Hence, we show that HPWS fuels the personal resources of employees, and enhances thriving at work. This is important as employees who perceive to be thriving at work, are better able to perform their jobs, and indeed contribute more with respect to task performance, and OCB. Moreover, the study also shows that less proactive employees may have higher needs to receive formal practices by the organizations to obtain working conditions which stimulate them to thrive at work. These findings extend the prior HPWS literature and offer important implications for organization practices.

\section{Theoretical Contributions}

Our study contributes to previous research in many ways. Firstly, by testing the mediating effects of social exchange and thriving, our study highlights on the influence processes whereby HPWS facilitates employee performance, and responds to the calls proposed in prior HPWS research. Researchers recommended that future research should follow distinctive approaches in order to better elucidate the process where HPWS promotes individual desirable attitudes and behaviors (Jiang et al., 2013). Prior work has drawn upon social exchange, and human capital theory to explore how HPWS affects employee performance (Liao et al., 2009; Takeuchi et al., 2007). However, such mediating relationships fail to fully capture personal resource linkages that may have considerable influences on employee consequences (Clauss et al., 2018; Xanthopoulou et al., 2009).

Our findings show that after controlling for the human capital mechanism (i.e., 
competence), HPWS indirectly affects employee task performance and OCB through thriving and social exchange. That is, thriving is a novel explanatory mechanism linking HPWS to employee performance, and has the incremental contribution over and above the social exchange approach and the human capital view. Moreover, the results of Model 2 and Model 4 in Table 3 displayed the positive relationships between HPWS and employee task performance $(\gamma=0.38, p$ $<0.05)$ and OCB $(\gamma=0.58, p<0.01)$ when simultaneously adding HPWS and mediators (social exchange, thriving, as well as employee competence) as predictors, which suggest that there may be other mediators accounting for such relationships, such as organization based self esteem (OBSE). OBSE termed as "the self-perceived value that individuals have of themselves as organization members acting within an organizational context" (Pierce et al., 1989: 625). HPWS reflects organizations' investment in employees, and communicates messages with employees concerning organizations value them (Liu et al., 2013). As a consequence, we argue that HPWS may boost employee OBSE. We encourage scholars to conduct additional research testing whether HPWS facilitates employee task performance and OCB via OBSE. ${ }^{4}$

Furthermore, by examining the moderating role of employee proactive personality, this study identifies a boundary condition under which organizations can reap more benefits from HPWS. Previous HPWS research had almost exclusively concentrated the moderating impacts of situational factors e.g. team characteristics i.e. team cohesion, task complexity (Chang et al., 2014), and leadership styles e.g., empowerment leadership and service leadership (Chuang et al., 2016; Jiang et al., 2015). However, few researchers tried how personality traits influence HPWS and employee performance. This study postulates that the cross-level influence of HPWS on thriving relies on employee proactive personality. Furthermore, we suggest that proactive personality weakens the association between HPWS and thriving. This result complements prior

\footnotetext{
${ }^{4}$ We are thankful to the anonymous reviewer for this suggestion.
} 
HPWS literature investigating the moderating effects of environmental factors. Additionally, there exists an argument between the universalistic contingency approach in the HPWS research (Delery \& Doty, 1996).

Universalistic approach posits that there is an ideal HPWS which can drive organizational performance in any conditions for any organizations. Yet, contingency approach emphasizes that the extent to which HPWS facilitates organizational performance depends on certain boundary conditions. Consistent with the prediction of contingency approach, this study finds that the link between HPWS and thriving is positive and significant when employee proactive personality is low but a nonsignificant relationship when employee proactive personality is high. Thus, the results of the current study lend support to the contingency approach. Moreover, we do not propose the hypothesis that employee proactive personality moderates the effect of HPWS on social exchange because there is no theoretical study or empirical evidence that guides this prediction. However, we ran the analysis by adding social exchange as an outcome of the interaction effect between HPWS and proactive personality but the result was not significant $(\gamma=$ $-0.19, n s)$.

Moreover, a multilevel design our study uses is a strength as well. Some recent studies on the black box of "HRM-outcomes" have suggested that the HRM research lacks the introduction of the multi-level paradigm (Jiang et al., 2013; Peccei and van de Voorde, in press). This is an important omission in that HR practices are usually perceived at the department level. Hence, it is necessary to utilize the multi-level approach in the research on HPWS. Our findings also respond to and extend the HPWS literature.

Finally, our study contributes towards thriving literature. Past studies have shown that thriving is the result of individual characteristics, and contextual factors e.g. involvement climate 
(Wallace et al., 2016), servant leadership (Walumbwa et al., 2018), transformational leadership (Niessen et al., 2017), psychological capital (Paterson et al., 2014), promotion focus, and prevention focus (Wallace et al., 2016). Thus far, there has been limited insight into the issue of whether HPWS results in thriving. We found that HPWS is a situational trigger, and that thriving is a mechanism to employee performance, enrich our understanding of the enablers that shape thriving.

\section{Practical Implications}

The present study offers some important implications for both managers and organizations. We find that HPWS is a key predictor of employee task performance as well as OCB. This result suggests that the investment in HPWS pays off. As a result, managers have to pay more responsiveness to the implementation of HPWS in their organizations. Research has suggested that supervisors' HR responsibility and goal congruence with their organizations are the pivotal factors facilitating their implementation efforts of HPWS (Whittaker \& Marchington, 2003; Zhang et al., 2018). Thus, the implementation of HPWS should be included in supervisor's job description. In addition, when supervisors' goals are aligned with the goals of their organizations, mutually beneficial outcomes may happen (Ozcelik, 2013). HPWS implementation is a very effective approach to achieve organizational objectives (Becker \& Gerhart, 1996). As a consequence, firms should take the interests of supervisors into full consideration when designing organizational strategies, which enables supervisors to effectively carry out HPWS

Moreover, the same care should be paid on thriving that also enhances employee performance. Previous research has shown that thriving can be promoted through decisionmaking discretion, and building up involvement climate (Wallace et al., 2016; Porath et al., 2012). Therefore, managers should provide job autonomy as well as opportunities in 
participative decision-making for employees to feel energized by the work they do. Besides, the implementation of HPWS is costly. Hence, managers should be aware of the boundary conditions under which organizations can gain more benefits from HPWS. We find that HPWS and employee proactive personality may substitute each other in predicting thriving. Consequently, managers should avoid the "one-size-fits-all" logic and think through individual differences which can enable organizations to make optimized choices with regard to the implementation of HPWS.

\section{Study Limitations and Future Research Directions}

Our study has number of limitations needed that future researchers may explore. Firstly, we collected multi-level data i.e., employees and department supervisors that mitigated the possible influences of CMV in our findings. Though, our the data were cross-sectional data which limited the ability to derive conclusions from causal inferences. As the data was from number of sources and bootstrapped the regression analyses to obtain robust results but it might have been that higher performing employees experience thriving at work, and may be more likely to be offered HPWS by their managers. Hence, reversed causality might exist. Thus, future research may utilize longitudinal research designs to thoroughly test the causal relationships over time. Secondly, we conducted research in China, the generalizability issues may arise for other contexts. Consequently, we recommend future researchers to test whether our results correspond to other contexts.

Thirdly, we used department supervisors to report HPWS. Research has argued that department supervisors assume more HR obligations (e.g. performance appraisal reports, recruitment and selection, training and development, and promotion) today (Jiang, 2013; Kuvaas et al., 2014). Department supervisors may obtain information about HPWS from HR 
departments, and convey HR best practices to employees. Consequently, department supervisors play a crucial role in the implementation of HPWS (Sikora \& Ferris, 2014; Brewster et al., 2013). Similarly, some researchers have used department supervisors to assess HPWS (Jensen et al., 2013; Pak \& Kim, in press; Sikora et al., 2015). However, such method did carry weakness to the present research e.g. HPWS rated by department supervisors may not be consistent with employee experienced HPWS. Extant research has indeed suggested that this misalignment may exist (Liao et al., 2009; Nishii \& Wright, 2008), as managers may have imperfect understanding of the available HR practices as well as the needs of their employees for availability of HRM. Future research should explore the aspects that constricted the discrepancy between departmentlevel HPWS as well as employee-level HPWS.

Another suggestion for future research pertains to the question of how HPWS may contribute to employee thriving at work. We have used a personal resources perspective to argue that employees may thrive at work when appropriate HPWS is available to them. However, future research may dig deeper into the issue of how the bundles of practices make employees thrive in their jobs. For instance, it may be that employees may perceive HPWS as contributing to a perception of organizations as taking care of all the different aspects of the employment relationships (such as performance management, training, and development), and that these positive attributions of the organizations contribute to psychological safety and a feeling that one is thriving at work.

\section{Conclusion}

This study integrated a personal resources perspective and a social exchange approach to theorize and examine the mediating mechanisms between HPWS and employee performance. With cross-level data, results indicated that thriving and social exchange mediated the impact of 
HPWS on employee performance. In addition, we hypothesized and found that HPWS and employee proactive personality reduced the impact of one another on employee thriving. Through this study, we not only extend new knowledge about how HPWS affects employee performance but also encourage researchers to discover other explanatory links to the HPWSperformance association. 


\section{References}

Aiken, L. S., \& West, S. G. 1991. Multiple regression: Testing and interpreting interactions. Thousand Oaks, CA: Sage.

Aryee, S., Walumbwa, F. O., Seidu, E. Y., \& Otaye, L. E. 2012. Impact of high-performance work systems on individual-and branch-level performance: Test of a multilevel model of intermediate linkages. Journal of Applied Psychology, 97(2): 287-300.

Aryee, S., Walumbwa, F. O., Seidu, E. Y., \& Otaye, L. E. 2016. Developing and leveraging human capital resource to promote service quality: Testing a theory of performance. Journal of Management, 42(2): 480-499.

Bagozzi, R. P., \& Edwards, J. R. 1998. A general approach for representing constructs in organizational research. Organizational Research Methods, 1(1): 45-87.

Bakker, A. B., Tims, M., \& Derks, D. 2012. Proactive personality and job performance: The role of job crafting and work engagement. Human Relations, 65(10): 1359-1378.

Becker, B., \& Gerhart, B. 1996. The impact of human resource management on organizational performance: Progress and prospects. Academy of Management Journal, 39(4): 779-801.

Bowen, D. E., \& Ostroff, C. 2004. Understanding HRM-firm performance linkages: The role of the "strength" of the HRM system. Academy of Management Review, 29(2): 203-221.

Bateman, T. S., \& Crant, J. M. 1993. The proactive component of organizational behavior: A measure and correlates. Journal of Organizational Behavior, 14(2): 103-118.

Blau, P. M. 1964. Exchange and Power in Social Life. New York, NY: Wiley.

Brewster, C., Gollan, P. J., \& Wright, P. M. 2013. Guest editors' note: Human resource management and the line. Human Resource Management, 52(6): 829-838.

Brown, D. J., Cober, R. T., Kane, K., Levy, P. E., \& Shalhoop, J. 2006. Proactive personality and 
the successful job search: A field investigation with college graduates. Journal of Applied Psychology, 91(3): 717-726.

Buruck, G., Dörfel, D., Kugler, J., \& Brom, S. S. 2016. Enhancing well-being at work: The role of emotion regulation skills as personal resources. Journal of Occupational Health Psychology, 21(4): 480-493.

Carmeli, A., \& Spreitzer, G. M. 2009. Trust, connectivity, and thriving: Implications for innovative behaviors at work. Journal of Creative Behavior, 43(3): 169-191.

Chang, P. C., \& Chen, S. J. 2011. Crossing the level of employee's performance: HPWS, affective commitment, human capital, and employee job performance in professional service organizations. International Journal of Human Resource Management, 22(4): 883901.

Chang, S., Jia, L., Takeuchi, R., \& Cai, Y. 2014. Do high-commitment work systems affect creativity? A multilevel combinational approach to employee creativity. Journal of Applied Psychology, 99(4): 665-680.

Chen, Z. X., Tsui, A. S., \& Farh, J. L. 2002. Loyalty to supervisor vs. organizational commitment: Relationships to employee performance in China. Journal of Occupational and Organizational Psychology, 75(3): 339-356.

Chuang, C. H., Jackson, S. E., \& Jiang, Y. 2016. Can knowledge-intensive teamwork be managed? Examining the roles of HRM systems, leadership, and tacit knowledge. Journal of Management, 42(2): 524-554.

Clauss, E., Hoppe, A., O’shea, D., González Morales, M. G., Steidle, A., \& Michel, A. 2018. Promoting personal resources and reducing exhaustion through positive work reflection among caregivers. Journal of Occupational Health Psychology, 23(1): 127-140. 
Colquitt, J. A., Baer, M. D., Long, D. M., \& Halvorsen-Ganepola, M. D. 2014. Scale indicators of social exchange relationships: A comparison of relative content validity. Journal of Applied Psychology, 99(4): 599-618.

Crant, J. M. 2000. Proactive behavior in organizations. Journal of Management, 26(3): 435-462.

Cullen, K. L., Gerbasi, A., \& Chrobot-Mason, D. 2018. Thriving in central network positions: The role of political skill. Journal of Management, 44(2): 628-706.

Datta, D. K., Guthrie, J. P., \& Wright, P. M. 2005. Human resource management and labor productivity: Does industry matter? Academy of Management Journal, 48(1): 135-145.

Delery, J. E., \& Doty, D. H. 1996. Modes of theorizing in strategic human resource management: Tests of universalistic, contingency, and configurational performance predictions. Academy of Management Journal, 39(4): 802-835.

Ellis, H. C. 1965. The transfer of learning. New York, NY: MacMillan.

Farh, J. L., Hackett, R. D., \& Liang, J. 2007. Individual-level cultural values as moderators of perceived organizational support-employee outcome relationships in China: Comparing the effects of power distance and traditionality. Academy of Management Journal, 50(3): 715729.

Fredrickson, B. L. 2001. The role of positive emotions in positive psychology: The broaden-andbuild theory of positive emotions. American Psychologist, 56(3): 218-226.

Gardner, T. M., Wright, P. M., \& Moynihan, L. M. 2011. The impact of motivation, empowerment, and skill-enhancing practices on aggregate voluntary turnover: The mediating effect of collective affective commitment. Personal Psychology, 64(2): 315-350.

Gerbasi, A., Porath, C. L., Parker, A., Spreitzer, G., \& Cross, R. 2015. Destructive de-energizing relationships: How thriving buffers their effect on performance. Journal of Applied 
Psychology, 100(5): 1423-1433.

Gilbert, E., Foulk, T., \& Bono, J. 2018. Building personal resources through interventions: An integrative review. Journal of Organizational Behavior, 39(2): 214-228.

Greguras, G., \& Diefendorff, J. M. 2010. Why does proactive personality predict employee life satisfaction and work behaviors? A field investigation of the mediating role of the selfconcordance model. Personnel Psychology, 63(3): 539-560.

Guthrie, J. P. 2001. High-involvement work practices, turnover, and productivity: Evidence from New Zealand. Academy of Management Journal, 44(1): 180-190.

Hair, J. F., Hult, G. T. M., Ringle, C. M., \& Sarstedt, M. 2013. A primer on partial least squares structural equation modeling (PLS-SEM). Thousand Oaks, CA: Sage.

Hobfoll, S. E. 1989. Conservation of resources: A new attempt at conceptualizing stress. American Psychologist, 44(3): 513-524.

Hobfoll, S. E. 2001. The influence of culture, community, and the nested-self in the stress process: Advancing conservation of resources theory. Applied Psychology, 50(3): 337-421.

Hobfoll, S. E., Johnson, R. J., Ennis, N., \& Jackson, A. P. (2003). Resource loss, resource gain, and emotional outcomes among inner city women. Journal of Personality and Social Psychology, 84, 632-643.

Hofmann, D. A., \& Gavin, M. B. 1998. Centering decisions in hierarchical linear models: Implications for research in organizations. Journal of Management, 24(5): 623-641.

Hoyle, R. H. 1995. Structural equation modeling: Concepts, issues, and applications. Thousand Oaks, CA: SAGE.

Jensen, J. M., Patel, P. C., \& Messersmith, J. G. 2013. High-performance work systems and job control: Consequences for anxiety, role overload, and turnover intentions. Journal of 
Management, 39(6): 1699-1724.

Jiang, K. 2013. Bridging the gap between reality and perception: Managers'role in shaping employee perceptions of high performance work systems. Rutgers University-Graduate School-New Brunswick.

Jiang, K., Chuang, C. H., \& Chiao, Y. C. 2015. Developing collective customer knowledge and service climate: The interaction between service-oriented high-performance work systems and service leadership. Journal of Applied Psychology, 100(4): 1089-1106.

Jiang, K., Lepak, D. P., Hu, J., \& Baer, J. C. 2012. How does human resource management influence organizational outcomes? A meta-analytic investigation of mediating mechanisms. Academy of Management Journal, 55(6): 1264-1294.

Jiang, K., Takeuchi, R., \& Lepak, D. P. 2013. Where do we go from here? New perspectives on the black box in strategic human resource management research. Journal of Management Studies, 50(8): 1448-1480.

Kehoe, R. R., \& Collins, C. J. 2017. Human resource management and unit performance in knowledge-intensive work. Journal of Applied Psychology, 102(8): 1222-1236.

Kehoe, R. R., \& Wright, P. M. 2013. The impact of high-performance human resource practices on employees' attitudes and behaviors. Journal of Management, 39(2): 366-391.

Korff, J., Biemann, T., \& Voelpel, S. C. 2017. Human resource management systems and work attitudes: The mediating role of future time perspective. Journal of Organizational Behavior, 38(1): 45-67.

Kuvaas, B., Dysvik, A., \& Buch, R. 2014. Antecedents and employee outcomes of line managers' perceptions of enabling HR practices. Journal of Management Studies, 51(6): 845-868. 
Lam, C. F., Liang, J., Ashford, S. J., \& Lee, C. 2015. Job insecurity and organizational citizenship behavior: Exploring curvilinear and moderated relationships. Journal of Applied Psychology, 100(2): 499-510.

Li, N., Harris, T. B., Boswell, W. R., \& Xie, Z. 2011. The role of organizational insiders' developmental feedback and proactive personality on newcomers' performance: An interactionist perspective. Journal of Applied Psychology, 96(6): 1317-1327.

Liao, H., Toya, K., Lepak, D. P., \& Hong, Y. 2009. Do they see eye to eye? Management and employee perspectives of high-performance work systems and influence processes on service quality. Journal of Applied Psychology, 94(2): 371-391.

Little, T. D., Cunningham, W. A., Shahar, G., \& Widaman, K. F. 2002. To parcel or not to parcel: Exploring the question, weighing the merits. Structural Equation Modeling, 9(2): 151-173.

Liu, D., Gong, Y., Zhou, J., \& Huang, J. C. 2017. Human resource systems, employee creativity, and firm innovation: the moderating role of firm ownership. Academy of Management Journal, 60(3): 1164-1188.

Liu, J., Lee, C., Hui, C., Kwan, H. K., and Wu, L. Z. 2013. Idiosyncratic deals and employee outcomes: The mediating roles of social exchange and self-enhancement and the moderating role of individualism. Journal of Applied Psychology, 98(5): 832-840.

Lopez-Cabrales, A., Pérez-Luño, A., \& Cabrera, R. V. 2009. Knowledge as a mediator between HRM practices and innovative activity. Human Resource Management, 48(4): 485-503.

Major, D. A., Turner, J. E., \& Fletcher, T. D. 2006. Linking proactive personality and the big five to motivation to learn and development activity. Journal of Applied Psychology, 91(4): 927935.

Messersmith, J. G., Patel, P. C., \& Lepak, D. P. 2011. Unlocking the black box: Exploring the 
link between high-performance work systems and performance. Journal of Applied Psychology, 96(6): 1105-1118.

Niessen, C., Mäder, I., Stride, C., \& Jimmieson, N. L. 2017. Thriving when exhausted: The role of perceived transformational leadership. Journal of Vocational Behavior, 103 (Part B): 4151.

Niessen, C., Sonnentag, S., \& Sach, F. 2012. Thriving at work-A diary study. Journal of Organizational Behavior, 33(4): 468-487.

Nieves, J., \& Quintana, A. 2018. Human resource practices and innovation in the hotel industry: The mediating role of human capital. Tourism and Hospitality Research, 18(1): 72-83.

Nishii, L. H., \& Wright, P. 2008. Variability within organizations: Implications for strategic human resource management. In D. B. Smith (ed.), The people make the place (pp. 225248). Mahwah, NJ: Lawrence Erlbaum Associates.

Organ, D. W. 1988. Organizational Citizenship Behavior: The Good Soldier Syndrome. Lexington, MA: Lexington.

Ozcelik, H. 2013. An empirical analysis of surface acting in intra-organizational relationships. Journal of Organizational Behavior, 34(3): 291-309.

Pak, J., \& Kim, S. in press. Team manager's implementation, high performance work systems intensity, and performance: A multilevel investigation. Journal of Management.

Paterson, T. A., Luthans, F., \& Jeung, W. 2014. Thriving at work: Impact of psychological capital and supervisor support. Journal of Organizational Behavior, 35(3): 434-446.

Peccei, R., \& Van De Voorde, K. in press. The application of the multilevel paradigm in human resource management-outcomes research: Taking stock and going forward. Journal of Management. 
Pierce, J. L., Gardner, D. G., Cummings, L. L., \& Dunham, R. B. 1989. Organization-based selfesteem: Construct definition, measurement, and validation. Academy of Management Journal, 32(3): 622-648.

Porath, C., Spreitzer, G., Gibson, C., \& Garnett, F. G. 2012. Thriving at work: Toward its measurement, construct validation, and theoretical refinement. Journal of Organizational Behavior, 33(2): 250-275.

Preacher, K. J., \& Selig, J. P. 2012. Advantages of Monte Carlo confidence intervals for indirect effects. Communication Methods and Measures, 6(2): 77-98.

Raineri, A. 2017. Linking human resources practices with performance: the simultaneous mediation of collective affective commitment and human capital. International Journal of Human Resource Management, 28(22): 3149-3178.

Seibert, S. E., Crant, J. M., \& Kraimer, M. L. 1999. Proactive personality and career success. Journal of Applied Psychology, 84(3): 416-427.

Seibert, S. E., Kraimer, M. L., \& Crant, J. M. 2001. What do proactive people do? A longitudinal model linking proactive personality and career success. Personnel Psychology, 54(4): 845874.

Sheldon, K. M., Elliot, A. J., Kim, Y., \& Kasser, T. 2001. What is satisfying about satisfying events? Testing 10 candidate psychological needs. Journal of Personality and Social Psychology, 80(2): 325-339.

Shore, L. M., Tetrick, L. E., Lynch, P., \& Barksdale, K. 2006. Social and economic exchange: Construct development and validation. Journal of Applied Social Psychology, 36(4): 837867.

Sikora, D. M., \& Ferris, G. R. 2014. Strategic human resource practice implementation: The 
critical role of line management. Human Resource Management Review, 24(3): 271-281.

Sikora, D. M., Ferris, G. R., \& Van Iddekinge, C. H. 2015. Line manager implementation perceptions as a mediator of relations between high-performance work practices and employee outcomes. Journal of Applied Psychology, 100(6): 1908-1918.

Song, L. J., Tsui, A. S., \& Law, K. S. 2009. Unpacking employee responses to organizational exchange mechanisms: The role of social and economic exchange perceptions. Journal of Management, 35(1): 56-93.

Spreitzer, G. M., \& Porath, C. 2014. Self-determination as a nutriment for thriving: Building an integrative model of human growth at work. In M. Gagne (ed.), The Oxford handbook of work engagement, motivation, and self-determination theory. New York: Oxford University Press.

Spreitzer, G., Sutcliffe, K., Dutton, J., Sonenshein, S., \& Grant, A. M. 2005. A socially embedded model of thriving at work. Organization Science, 16(5): 537-549.

Subramony, M. 2009. A meta-analytic investigation of the relationship between HRM bundles and firm performance. Human Resource Management, 48(5): 745-768.

Sun, L. Y., Aryee, S., \& Law, K. S. 2007. High-performance human resource practices, citizenship behavior, and organizational performance: A relational perspective. Academy of Management Journal, 50(3): 558-577.

Takeuchi, R., Chen, G., \& Lepak, D. P. 2009. Through the looking glass of a social system: Cross-level effects of high-performance work systems on employees' attitudes. Personnel Psychology, 62(1): 1-29.

Takeuchi, R., Lepak, D. P., Wang, H., \& Takeuchi, K. 2007. An empirical examination of the mechanisms mediating between high-performance work systems and the performance of 
Japanese organizations. Journal of Applied Psychology, 92(4): 1069-1083.

Úbeda-García, M., Claver-Cortés, E., Marco-Lajara, B., Zaragoza-Sáez, P., \& García-Lillo, F. (2018). High performance work system and performance: Opening the black box through the organizational ambidexterity and human resource flexibility. Journal of Business Research, 88, 397-406.

Vermeeren, B. 2014. Variability in HRM implementation among line managers and its effect on performance: A 2-1-2 mediational multilevel approach. International Journal of Human Resource Management, 25(22): 3039-3059.

Wallace, J. C., Butts, M. M., Johnson, P. D., Stevens, F. G., \& Smith, M. B. 2016. A multilevel model of employee innovation: Understanding the effects of regulatory focus, thriving, and employee involvement climate. Journal of Management, 42(4): 982-1004.

Walumbwa, F. O., Muchiri, M. K., Misati, E., Wu, C., \& Meiliani, M. 2018. Inspired to perform: A multilevel investigation of antecedents and consequences of thriving at work. Journal of Organizational Behavior, 39(3): 249-261.

Whittaker, S., \& Marchington, M. 2003. Devolving HR responsibility to the line: Threat, opportunity or partnership? Employee Relations, 25(3), 245-261.

Xanthopoulou, D., Bakker, A. B., Demerouti, E., \& Schaufeli, W. B. 2009. Reciprocal relationships between job resources, personal resources, and work engagement. Journal of Vocational Behavior, 74(3): 235-244.

Zhang, J. W., Akhtar, M. N., Bal, P. M., Zhang, Y. J., \& Talat, U. 2018. How do highperformance work systems affect individual outcomes: A multilevel perspective. Frontiers in Psychology, 9(586): 1-13. doi: 10.3389/fpsyg.2018.00586. 
Table 1 Comparison of Measurement Models

\begin{tabular}{lccccccc}
\hline \multicolumn{1}{c}{ Model } & $\chi^{2}$ & $d f$ & $\chi^{2} / d f$ & $\Delta \chi^{2}(\Delta d f)$ & RMSEA & TLI & CFI \\
\hline Six-factor base model & 768.99 & 260 & 2.96 & & 0.07 & 0.90 & 0.91 \\
Five-factor model 1 & 879.99 & 265 & 3.32 & $111.00^{* * *}(5)$ & 0.08 & 0.88 & 0.89 \\
Five-factor model 2 & 1012.12 & 265 & 3.82 & $243.13^{* * *}(5)$ & 0.09 & 0.85 & 0.87 \\
Five-factor model 3 & 953.22 & 265 & 3.60 & $184.23^{* * *}(5)$ & 0.08 & 0.86 & 0.88 \\
Five-factor model 4 & 999.26 & 265 & 3.77 & $230.27^{* * *}(5)$ & 0.08 & 0.85 & 0.87 \\
Three-factor model & 1480.32 & 272 & 5.44 & $711.33^{* * *}(12)$ & 0.11 & 0.77 & 0.79 \\
One-factor model & 3448.73 & 275 & 12.54 & $2679.74^{* * * *}(15)$ & 0.17 & 0.39 & 0.44 \\
\hline
\end{tabular}

Note. $N=391 .{ }^{* * *} p<0.001$.

RMSEA = root mean square error of approximation. TLI =Tucker-Lewis index. CFI=comparative fit index

Six-factor base model: thriving, social exchange, competence, task performance, OCB, and proactive personality.

Five-factor model 1: thriving and social exchange were combined into one factor.

Five-factor model 2: thriving and competence were combined into one factor.

Five-factor model 3: task performance and OCB were combined into one factor.

Five-factor model 4: thriving and proactive personality were combined into one factor.

Three-factor model: thriving, social exchange, and competence were combined into one factor; task performance and OCB were combined into one factor. One-factor model: all six factors were combined into one factor. 
Table 2. Means, Standard Deviations, and Correlations Among Study Variables

\begin{tabular}{|c|c|c|c|c|c|c|c|c|c|c|c|}
\hline Variables & $M$ & $S D$ & 1 & 2 & 3 & 4 & 5 & 6 & 7 & 8 & 9 \\
\hline \multicolumn{12}{|l|}{ Level 1 variables } \\
\hline 1. Gender & 0.47 & - & & & & & & & & & \\
\hline 2. Age & 29.28 & 5.80 & 0.02 & & & & & & & & \\
\hline 3. Education level & 2.92 & 0.47 & 0.07 & -0.07 & & & & & & & \\
\hline 4. Tenure & 4.69 & 4.70 & 0.03 & $0.72^{* * * *}$ & $-0.12^{*}$ & & & & & & \\
\hline 5. Social exchange & 3.58 & 0.72 & -0.04 & -0.07 & $0.10^{*}$ & $-0.13^{* *}$ & & & & & \\
\hline 6.Employee competence & 4.04 & 0.76 & -0.01 & 0.04 & -0.06 & $0.13^{*}$ & $0.39^{* * * *}$ & & & & \\
\hline 7. Thriving & 3.89 & 0.64 & 0.01 & 0.09 & 0.03 & 0.01 & $0.59^{* * *}$ & $0.41^{* * *}$ & & & \\
\hline 8.Task performance & 5.55 & 1.07 & 0.03 & $0.13^{* *}$ & 0.01 & $0.14^{* *}$ & $0.22^{* * * *}$ & $0.29^{* * *}$ & $0.33^{* * *}$ & & \\
\hline 9. ОСВ & 5.26 & 1.09 & 0.01 & $0.23^{* * *}$ & -0.05 & $0.17^{* * *}$ & $0.16^{* *}$ & $0.22^{* * *}$ & $0.27^{* * * *}$ & $0.73^{* * *}$ & \\
\hline 10.Proactive personality & 3.74 & 0.59 & -0.05 & 0.05 & 0.02 & $0.10^{*}$ & $0.33^{* * *}$ & $0.48^{* * *}$ & $0.44^{* * *}$ & $0.27^{* * *}$ & $0.32^{* * *}$ \\
\hline \multicolumn{12}{|l|}{ Level 2 variables } \\
\hline 1. Department size & 18.98 & 14.58 & & & & & & & & & \\
\hline 2. HPWS & 3.92 & 0.73 & 0.12 & & & & & & & & \\
\hline \multicolumn{12}{|l|}{ Level 3 variables } \\
\hline 1. Firm size & 1.48 & 0.68 & & & & & & & & & \\
\hline 2. Firm age & 16.53 & 17.13 & 0.05 & & & & & & & & \\
\hline
\end{tabular}

Note. $N($ Level 1) $=391, N($ Level 2) $=84, N($ Level 3) $=21$. Gender: $0=$ male, 1 =female.

Education level: 1 =junior high school and below, 2 = senior high school, 3 = college or undergraduate, 4 =postgraduate and over.

Firm size: $1=$ less than 500, 2 =between 500 and 2000, $3=$ more than 2000 .

${ }^{*} p<0.05 .{ }^{* *} p<0.01$. ${ }^{* * *} p<0.001$. 
Table 3 Results of HLM Analyses

\begin{tabular}{|c|c|c|c|c|c|c|c|}
\hline \multirow{2}{*}{$\begin{array}{l}\text { Outcome variables } \\
\text { Predicting variables }\end{array}$} & \multicolumn{2}{|c|}{ Task performance } & \multicolumn{2}{|c|}{ OCB } & \multicolumn{2}{|c|}{ Thriving } & \multirow{2}{*}{$\begin{array}{c}\text { Social exchange } \\
\text { Model } 7 \\
\end{array}$} \\
\hline & Model 1 & Model 2 & Model 3 & Model 4 & Model 5 & Model 6 & \\
\hline \multicolumn{8}{|l|}{ Level 1 variables } \\
\hline Gender & $-0.06(0.07)$ & $-0.04(0.06)$ & $-0.14^{*}(0.07)$ & $-0.09(0.05)$ & $-0.03(0.07)$ & $0.001(0.05)$ & $-0.09(0.06)$ \\
\hline Age & $-0.01(0.01)$ & $-0.01(0.01)$ & $0.01(0.01)$ & $0.003(0.01)$ & 0.007(0.007) & $0.01(0.01)$ & $-0.01(0.01)$ \\
\hline Education level & $0.06(0.15)$ & $0.02(0.14)$ & $0.03(0.18)$ & $-0.005(0.16)$ & $0.02(0.04)$ & $0.06(0.04)$ & $0.10(0.07)$ \\
\hline Social exchange & & $0.20^{*}(0.09)$ & & $0.16^{*}(0.06)$ & & & \\
\hline Employee competence & & $0.04(0.05)$ & & $0.02(0.05)$ & & & \\
\hline Thriving & & $0.16^{*}(0.06)$ & & $0.11^{*}(0.05)$ & & & \\
\hline $\begin{array}{l}\text { Proactive } \\
\text { personality }\end{array}$ & & & & & & $0.42^{* * * *}(0.06)$ & \\
\hline $\begin{array}{c}\text { Mean proactive } \\
\text { personality }\end{array}$ & & & & & & $0.23^{* *}(0.07)$ & \\
\hline $\begin{array}{l}\text { HPWS } \times \text { Mean } \\
\text { proactive personality }\end{array}$ & & & & & & $-0.19(0.19)$ & \\
\hline \multicolumn{8}{|l|}{ Level 3 variables } \\
\hline Firm size & $-0.07(0.13)$ & $-0.07(0.12)$ & $-0.13(0.13)$ & $-0.14(0.13)$ & $-0.02(0.06)$ & $-0.04(0.05)$ & $-0.01(0.06)$ \\
\hline Firm age & $0.001(0.004)$ & $0.003(0.004)$ & $0.004(0.004)$ & $0.004(0.005)$ & $-0.01(0.01)$ & $-0.01(0.01)$ & $-0.01(0.01)$ \\
\hline
\end{tabular}


Cross-level interaction

HPWS $\times$ Proactive

$-0.24^{* * * *}(0.05)$

personality

Note. $N($ Level 1) $=391, N($ Level 2) $=84, N($ Level 3 $)=21$.

Unstandardized coefficients were presented and the corresponding standard errors were reported in the parentheses.

${ }^{*} p<0.05$. ${ }^{* *} p<0.01 .{ }^{* * *} p<0.001$. 


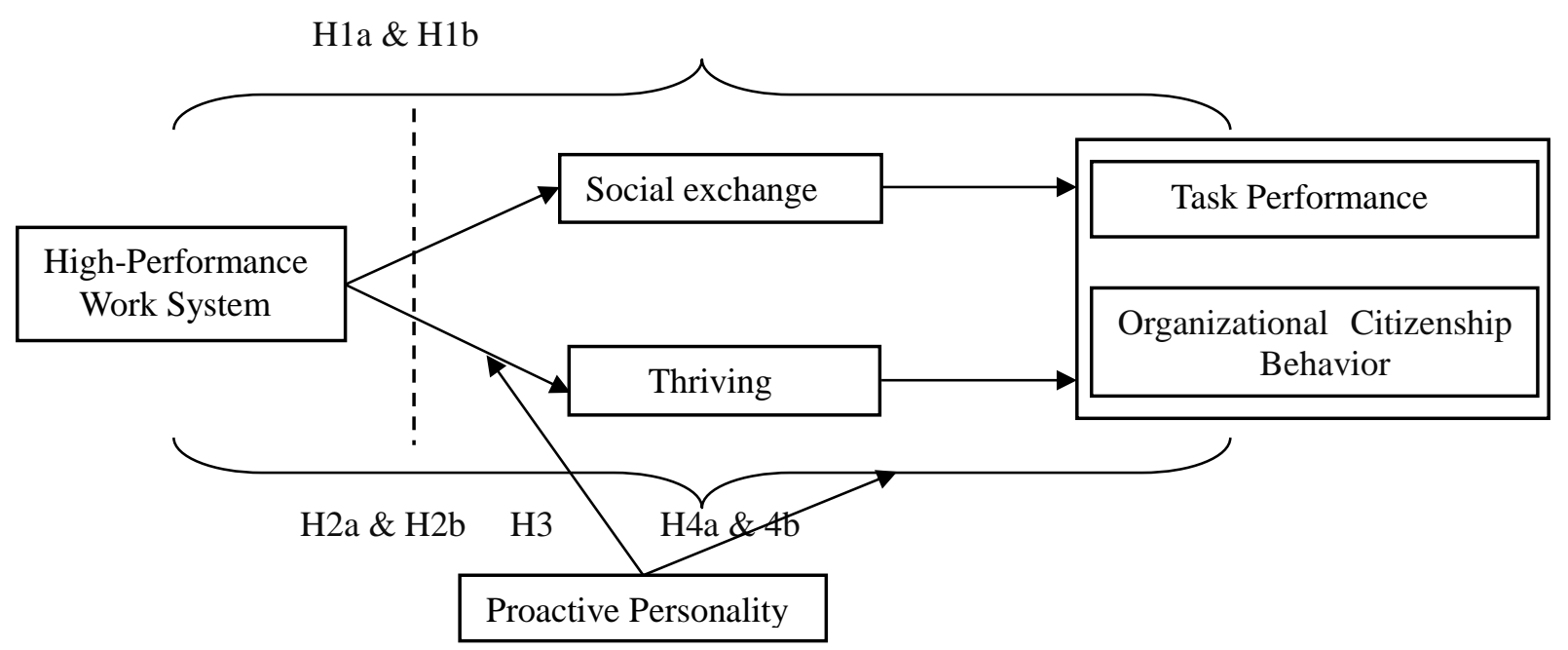

Figure 1 Theoretical Model of the Current Study

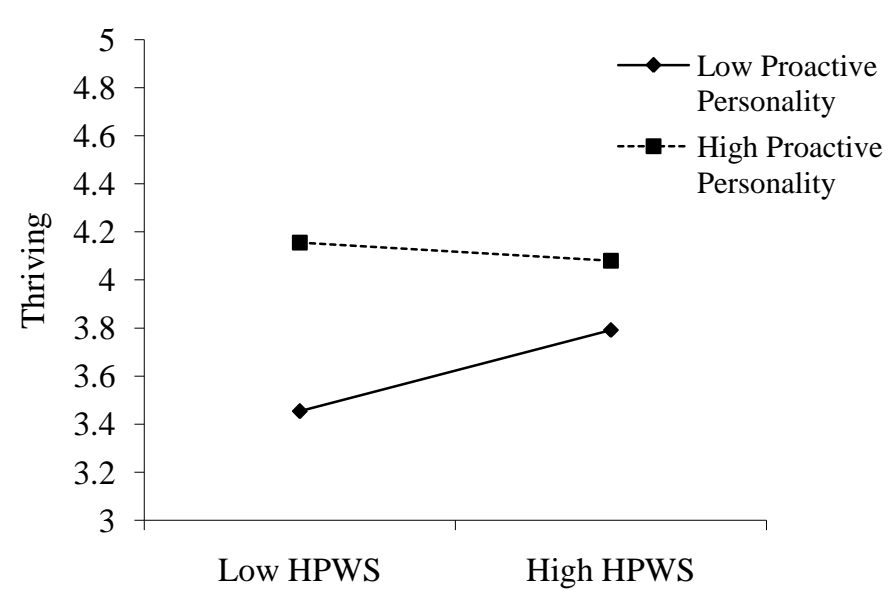

Figure 2 The Moderating Effect of Proactive Personality in the Relationship between HPWS and Thriving 